\title{
Narración y ficción en la investigación educativa y pedagógica: relaciones y límites disciplinares
}

\section{Storytelling and Fiction in Educational and Pedagogical Research: relationships and disciplinary boundaries}

\author{
Raquel Fernández Cobo*
}

Recibido: 23 de febrero de 2021 Aceptado: 4 de mayo de 2021 Publicado: 31 de enero de 2022

To cite this article: Fernández, R. (2022). La narración y la ficción en la investigación educativa y pedagógica: relaciones y límites disciplinares. Márgenes Revista de Educación de la Universidad de Málaga. 3(1), 7-24

DOI: http://dx.doi.org/10.24310/mgnmar.v3i1.12019

\section{RESUMEN}

A partir de los años 70 del pasado siglo hemos asistido, tanto en los estudios literarios como en las investigaciones educativas, no solo a un "giro narrativo" (McEwan y Egan, 1995) sino a un "giro autobiográfico" que aparece como una consecuencia más de la importante herencia romántica que ha gestado el panorama literario contemporáneo (desde el Bildungsroman hasta la autoficción). Así, este artículo pretende hacer un recorrido por las intersecciones y los cruces de los problemas que surgen cuando se aborda el tema desde una zona de borde interdisciplinar entre la Literatura y la Educación.

Palabras clave: giro narrativo; verdad; Bildungsroman; autoficción; enseñanza

\section{ABSTRACT}

From the 1970s onwards, we have witnessed, both in literary studies and in educational research, not only a "narrative turn" (McEwan and Egan 1995) but an "autobiographical turn" that appears as a consequence more of the important romantic inheritance that the contemporary literary scene has generated (from the Bildungsroman to the autoficción). Thus, this article aims to make a tour of the intersections and junctions of the problems that arise when the subject is approached from an area of interdisciplinary border between Literature and Education.

Keywords: narrative turn; truth; teaching; Bildungsroman; autofiction 


\section{INVESTIGAR EN LOS LÍMITES DE LAS DISCIPLINAS}

Desde 1996 las investigaciones generadas sobre la relación entre literatura y enseñanza consolidan la Didáctica de la lengua y la literatura como un campo atravesado por discusiones y polémicas que siguen vigentes en las investigaciones actuales. La Educación trabaja generalmente con resultados concretos y cifras - aunque es necesario aclarar que dependerá del enfoque de la investigación-; la literatura no pertenece al campo de la verificación sino, más bien, de la ficción. Cuando abordamos problemas de la esfera educativa cuya problematización necesita ser abordada desde categorías o formas de resolución pertenecientes a otras disciplinas, estamos trabajando en palabras de Analía Gerbaudo (2009, p. 165), en una zona de borde disciplinar. Así, en este artículo pretendemos hacer un recorrido por las interrelaciones y cruces que posibilitan aquellas investigaciones que participan tanto del campo literario como educativo. En este caso, se trata de demostrar la importancia que tienen la novela y los géneros del yo, tales como el diario, la autobiografía e, incluso, la autoficción, como modelos de formación que puedan restablecer e instituir prácticas e intervenciones en la esfera educativa (Gudmundsdottir 1995; McEwan 1995). Los estudios que siguen esta hipótesis tienen sus raíces en la obra fundacional de Gerald Graff, Professing Literature. An Institucional History (1987) y se apoyan en la recolección de datos que permitan la recuperación histórica y la construcción del conocimiento a través de la experiencia, recuperando aspectos de la vida humana que fueron negados en la epistemología de la investigación educativa. Ello supone un importante "giro narrativo" (McEwan y Egan 2005) para el progreso de las ciencias sociales que debe ser examinado en los cruces de su propia interdisciplinariedad, literatura, filosofía y educación, principalmente.

\section{LA NATURALEZA PEDAGÓGICA DE LA NARRATIVA}

Hacia fines de los 60 y principios de los 70 se produjo, como decíamos, un importante "giro hermenéutico e interpretativo" en el campo de la teoría e investigación en ciencias sociales, las cuales situaron la narrativa como una de las estrategias centrales del proceso de enseñanza y aprendizaje. Este "giro narrativo" es uno de los mayores cambios de la historia en la investigación educativa porque, al dejar de preocuparse por buscar la verdad absoluta de las teorías, empiezan a preocuparse en cómo los sujetos construyen su identidad y cómo la interpretan. Desde esta perspectiva, el conocimiento se construye, de manera inductiva, teniendo en cuenta lo subjetivo como componente esencial de la comprensión de la realidad. Los autores que siguen esta línea de investigación interpretativa y biográfica, conciben la narrativa como un acto primario de la mente transferible al arte desde la vida, en donde la voz propia de los sujetos de la investigación se convierte en el aparato central, negando, de este modo, la distancia entre investigador y objeto de investigación que el ideal positivista había establecido (Conelly y Clandinin 1988; McEwan y Egan 1995, Goodson 1995, 2004 Huberman 1995). Se entenderá la narración como una capacidad humana fundamental; una condición del aprendizaje de las formas más elaboradas del pensamiento y la escritura. El ser humano vive a través de historias que lo definen y le construyen una identidad. La narrativa, por tanto, nos ayuda a organizar nuestra experiencia para interpretar el mundo y hacer inteligibles nuestras acciones, tanto para nosotros mismos como para los que nos rodean. En definitiva, la comprensión del mundo por parte de los sujetos viene dada en relación a los relatos a los que esos sujetos tienen acceso y que interpretan a partir de su propia experiencia. 
La narración de la experiencia surge tal como se aprende una lengua. Mandler (1984) considera que el esquema del relato es semejante al aprendizaje de la gramática. Es una manera natural de contar las experiencias y una solución para un problema fundamental en la vida: la creación de un orden razonable a partir de la experiencia [...] El esquema narrativo clasifica y asigna significación a la información y la sitúa dentro de la narrativa. La familiaridad se alcanza por medio de la repetición y de la creación de relatos similares (Gudmundsdottir, 1995, p. 62-63).

En la misma dirección, McIntyre (1985) apunta que si a los niños se les priva de relatos se los convierte en tartamudos, en personas vacilantes, tanto en sus palabras como en sus actos. Así, siguiendo a Jackson (1995: 27-51), podemos afirmar que la narrativa tiene dos funciones: epistemológica y transformadora, como también ha señalado Jorge Larrosa (1996, 2009). Epistemológica porque, como decíamos, participamos y formamos parte de una determinada cultura por medio de los relatos que esa misma cultura integra y, el acto de reconocimiento de dichos relatos, nos aporta sentimiento y experiencia de comunidad. Las narraciones personales, por tanto, interactúan de manera continua con las estructuras sociales, políticas, culturales, institucionales, etc. Resulta evidente la afirmación de que el ser humano necesita poseer un conocimiento rudimentario de esos relatos para ser considerado mínimamente alfabetizado dentro de su propia cultura. No obstante, la función epistemológica de la narrativa ha generado un gran campo de discusiones en torno a cuáles son los relatos que debemos conocer para formar parte de cierta cultura, cuáles deben ser enseñados y cuáles deben ser dejados fuera y por qué. Discusión que a su vez tiene mucho que ver con los objetivos educacionales y otras políticas que se pretendan llevar a cabo en el proceso de integración social. La función transformadora, en cambio, va ligada al carácter ontológico que poseen los relatos en sí mismos. La estructura narrativa es una característica de la conciencia humana, es decir, de las historias por medio de las cuales relatamos el viaje de aprendizaje de la especie humana en general y el viaje de crecimiento personal que nos contamos a nosotros mismos, desde la infancia hasta la vejez, en particular. En este último caso, las narraciones son más frecuentes en la historia literaria que en la historia de las ideas, tal como constata Kundera en "La desprestigiada herencia de Cervantes":

En efecto, para mí el creador de la Edad Moderna no es solamente Descartes, sino también Cervantes. Es posible que sea esto lo que los dos fenomenólogos han dejado de tomar en consideración en su juicio sobre la Edad Moderna. Al respecto deseo decir: si es cierto que la filosofía y las ciencias han olvidado el ser del hombre, aún más evidente resulta que con Cervantes se ha creado un gran arte europeo que no es otra cosa que la exploración de este ser olvidado. En efecto, todos los grandes temas existenciales que Heidegger analiza en Ser y Tiempo, y que a su juicio han sido dejados de lado por toda la filosofía europea anterior, fueron revelados, expuestos, iluminados por cuatro siglos de novela (cuatro siglos de reencarnación europea de la novela). Uno tras otro, la novela ha descubierto por sus propios medios, por su propia lógica, los diferentes aspectos de la existencia: con los contemporáneos de Cervantes se pregunta qué es la aventura; con Samuel Richardson comienza a examinar «lo que sucede en el interior», a desvelar la vida secreta de los sentimientos; con Balzac descubre el arraigo del hombre en la Historia; con Flaubert explora la terra hasta entonces incógnita de lo cotidiano; con Tolstoi se acerca a la intervención de lo irracional en las decisiones y comportamiento humanos. La novela sondea el tiempo: el inalcanzable 


\section{EST U D O S Y E N A Y O S}

momento pasado con Marcel Proust; el inalcanzable momento presente con James Joyce. Se interroga con Thomas Mann sobre el papel de 105 mitos que, llegados del fondo de los tiempos, teledirigen nuestros pasos (Kundera, 1986).

Filósofos y novelistas, con sus historias de crecimiento personal, abrieron un camino acerca del análisis de la vida de las personas que ha seguido un tratamiento dentro de las investigaciones científicas más especializadas. Un sendero psicopatológico fundado por Freud, llega hasta los estudios de la personalidad de Murray (1967) y Allport (1968) y culmina con la brillante obra de Robert White, Live in progress, en 1952. Otro camino más sociológico fue iniciado recientemente por la "Escuela de Chicago" y el resurgimiento de la historia oral y la interacción simbólica en la Cultura (Thomas y Znaniecki 1984). Esta escuela produjo importantes trabajos acerca de la socialización del adulto.

Existe también un camino importante marcado por la psicología evolutiva que estudia los ciclos de vida a través de la autonarrativa. Estas investigaciones se apoyan en la idea de Polkinghorne de que "alcanzamos nuestra identidad y la idea de nosotros mismos por el uso de la configuración narrativa y totalizadora de nuestra experiencia comprendiéndola como la expresión de una historia simple que se revela" (cit. en Huberman, 1995, p. 150). Si esto es así, dice Huberman, "la narrativa se convierte entonces en el vehículo más adecuado tanto para captar la manera en que las personas constituyen su autoconocimento como para solicitarles que transmitan su sentido personal organizando su experiencia a lo largo de una dimensión temporal o secuencial” (1995, p. 187). Desde esta óptica, los trabajos de Jerome Bruner resultan particularmente reveladores: con Realidad mentaly mundos posibles (1986) y La fábrica de historias (2003), contribuyó a difundir en el campo de la investigación educativa una concepción del entendimiento que otorga un papel transcendental a la narrativa en nuestra actividad de dar sentido a la experiencia y al mundo, trabajos que resultaron fundacionales para el desarrollo de investigaciones en esta línea.

Desde un enfoque pedagógico, la narrativa ha encontrado aplicación práctica en la educación a través de dos campos diferenciados: el primero, el campo de la enseñanza de los contenidos, en donde se estudia el modo en que los maestros y profesores utilizan las narrativas para captar la atención de sus alumnos y el modo en que organizan lo que saben acerca de la enseñanza. Es decir, la manera en que "transforman el saber en decir" (White 1952). Ken Bain publicó en 2004 Lo que hacen los mejores profesores de universidad, en donde analiza el trabajo de setenta y tres profesores universitarios con el objetivo de responder a cuestiones tales como: ¿Qué es lo que hacen sobre cómo aprendemos? ¿Cómo preparan las clases? ¿Qué esperan de los estudiantes? ¿Cómo evalúan a sus estudiantes y a sí mismos? Y, en consecuencia, ¿cómo podemos aprender de ellos? Para Bain, el conocimiento pedagógico del contenido se desarrolla solo en la práctica, trabajando con textos, materiales y estudiantes año tras año. Considera la narrativa como una herramienta de trabajo que el profesor usa para dar sentido a la experiencia y para organizar un cuerpo de conocimiento práctico. Los buenos profesores saben qué historias contar, cuándo, a quién y con qué objetivos contarlas, proyectando cierto saber práctico que se puede ver en los programas de cátedra o en los apuntes de clase. Por esta razón, en las tres últimas décadas el tema de la narrativa, la enseñanza y el aprendizaje ha cobrado una importancia ecuménica en la investigación educativa. 
El segundo campo de la educación donde la narrativa encuentra un espacio básico es la investigación biográfico-narrativa. A pesar de que este método ha ganado consistencia epistemológica durante las últimas dos décadas, recorre una trayectoria breve y no goza de la legitimidad que debiera dentro del ámbito académico, hecho que, por otra parte, puede ser explicado con las palabras con las que Hyden White se refería a la historiografía contemporánea: "Una disciplina que produce relatos narrativos de su objeto como un fin en sí parece teóricamente poco sólida; una disciplina que investiga sus datos a fin de contar una historia sobre ellos parece metodológicamente deficiente" (1995, p. 41). Sin embargo, como afirma Ivor Goodson, primer gran difusor de este enfoque, las historias de vida son un género que ha recibido escasa atención en la mayoría de los países (2004, p. 27). Goodson funda este enfoque a principios de los años ochenta con la publicación de numerosas monografías sobre las historias de vida del profesorado. Dentro de la investigación biográfico-narrativa se llevan a cabo tres tipos de estudios: la narrativa en el currículum, la narrativa en la vida de los maestros y la narrativa de los investigadores acerca de las otras dos (Elbaz 1990, p. 366). Elbaz afirma que, cada vez más, la narrativa va floreciendo como objeto de interés de los investigadores en educación y, señala a los estudios de caso y la etnografía como los mejores métodos de indagación educativa. Clandinin y Conelly (1990) han denominado a estos últimos trabajos como "relatos de experiencias de indagación educativa" pues, como sostiene Alasdair McIntyre, "las instituciones y las prácticas sociales humanas tienen historias y nuestra comprensión de esas prácticas asume con frecuencia la forma de un relato” (cit. en McEwan 1995, p. 236). Así, las investigaciones de Conelly y Clandinin (1990, 1994, 1995), McEwan y Egan (1995) y Hargreaves (1999) recuperan la voz de los profesores utilizando diversos modos de recogida de datos - entrevistas, diarios, notas de campo de la experiencia, cartas, escritos autobiográficos y biografías, principalmente- donde van apresando los temas generadores de la vida de los informantes en pleno diálogo. Asimismo, los trabajos de Michael Huberman sobre narrativas biográficas también tratan de dar respuesta a cómo los maestros imaginan y construyen sus entornos institucionales en diferentes puntos de su carrera, sobre todo en los momentos de transición o de cambio, reconstruyendo, de este modo, "trayectorias profesionales y vitales" (Huberman 1984, 1995 y Huberman et al. 2000). Como en los estudios anteriores, emplea una metodología etnográfica, basada en el análisis de entrevistas biográficas a más de 170 informantes con el objetivo de captar el curso de la vida profesional de los maestros, tal como lo presentan ellos mismos en sus historias. De este modo, pretende avanzar progresivamente desde la narración hasta la teoría, pero siempre preservando las historias de vida de manera original como aparato en sus investigaciones. Es decir, la historia de vida no como un “archivo” de la investigación sino como "producto” en sí misma.

La cuestión es que las personas son historiadores revisionistas de su propio pasado y recordamos siempre de manera selectiva aquello que nos ayuda a entender mejor el presente. Las pruebas experimentales de estos trabajos indican que los recuerdos se componen de episodios o sucesos concretos que se recuerdan a grandes rasgos y configuran un fragmento de recuerdo, "el resto se rellena” admite Huberman (1995, p. 197). Es decir, entre fragmento y fragmento, existe un hueco de sentido que el sujeto "inventa" para poder dar coherencia al conjunto. No queremos decir con ello que el sujeto nos induzca a engaño intencionadamente, sino que en la forma de explicar lo vivido debe recurrir a la ficción a falta de un medio más idóneo para narrar la sucesión de una vida. La narración sirve, por tanto, para dar coherencia a esa experiencia perdida que la memoria 


\section{E S T U D I O Y E N S A Y S}

no puede recuperar pero, sobre todo, ayuda a mantener la estabilidad de la identidad a lo largo del tiempo. Los investigadores en ciencias sociales se ven enfrentados aquí a uno de los problemas más clásicos de las historias de vida: si es necesaria gran parte de invención para reconstruir históricamente el pasado, ¿es válida la indagación narrativa? ¿Puede trasferir la ficción una verdad?

\subsection{Narrativa y verdad}

Ya Herbert Spencer había afirmado en Educación intelectual, moral y física (1900) que un relato bien construido posee una especie de verdad real e inmediata. Conelly y Clandinin (2009), siguiendo la estela pedagógica de Spencer, en "Relatos de la experiencia e investigación narrativa”, sostienen que

la investigación narrativa en las ciencias sociales es una forma de narrativa empírica en la que los datos empíricos son centrales para el trabajo. La inevitable interpretación que se produce no coloca a la narrativa dentro de la ficción, aunque el lenguaje de investigación narrativa está profundamente ligado con términos derivados de la crítica literaria. (p. 34)

Por ello, no es de extrañar que para la mayoría de investigadores en educación las narrativas directamente literarias sean los mejores objetos de estudio, ya que no están manipuladas por la hermenéutica y otras formas de fenomenología social y psicológica.

Hemos olvidado que los novelistas han contribuido magníficamente a nuestra comprensión de nosotros mismos y de la compleja naturaleza humana. La narrativa, como manera de conocer y también como manera de organizar y comunicar la experiencia, ha perdido gran parte de la importancia que debería tener. El retorno a la narrativa significa que hoy reconsideramos el valor de la forma y la función de los relatos en todos los campos de la vida humana, especialmente la educación, donde se impuso un sesgo no narrativo y conductista. (McEwan 1995, p. 14)

Sin embargo, como apunta Huberman, utilizar directamente las fuentes literarias no es sencillo, puesto que algunas "son tan delirantes que, en ausencia del autor, nadie puede tener un verdadero acceso a ellas (como el Benjy de Faulkner en El sonido y la furia). Y, por último, las historias pueden ser ficcionales, deliberadamente redactadas para el caso, o producto de un autoengaño y nosotros no podemos determinar qué son” (1995, p. 225). Huberman considera que una solución para el campo educativo sería recoger el material sin intervenir y dejarlo sin analizar, como producto final y no como objeto de trabajo, tal y como se corresponde con las más antiguas tradiciones de la historia oral. El filósofo Heidegger se ha referido a esto como una manera de dejar que las cosas sean: el investigador pone en marcha el grabador y formula una pregunta general, casi siempre acerca de la vida del informante en relación con determinado periodo de la historia social, y luego se aparta del camino (Huberman 1995, p. 227). Finalmente se cotejaba esa historia oral y se triangulaba con otras fuentes de datos como archivos de periódico, cartas y otro material de archivo con el propósito de generar una historia social. Con ello se le da al lector una impresión real dando lugar a publicaciones con el nombre de "diarios de" o "cartas de". En este sentido, el escritor argentino Ricardo Piglia señala en Escenas de la novela argentina (clase 2, 08/09/2012), cómo el invento del grabador incide y supone, además del primer gesto de lectura 
contemporánea, una transformación en las formas de representación de la experiencia en los distintos campos de la cultura, no solo literaria. Y nos recuerda que Oscar Lewis, el antropólogo norteamericano, hizo dos libros absolutamente extraordinarios: Los hijos de Sánchez, que es la historia de vida de los miembros de una familia mexicana a los cuales él graba y, La vida, que son testimonios de las prostitutas puertorriqueñas de Nueva York, con las cuales él arma una suerte de relato oral que tuvo un impacto muy poderoso en la discusión sobre el futuro de la novela.

Y ahí surgió, diría yo, un camino de renovación de la narración muy conectado con la posibilidad de grabar las voces de sectores que hasta ese momento no habían tenido acceso a la palabra. En este sentido, hay toda una posibilidad que comienza a abrirse y comienza a influir sobre ciertos elementos de la tradición de la novela (Piglia, 2012, s.p).

Lewis también grabó las historias de vida de familias mexicanas para después transformarlas en una narración coral en su obra Antropología de la pobreza. Cinco Familias (1959). Oliver La Farge se interroga en el prefacio de este libro por la dificultad de este tipo de investigaciones y se pregunta hasta dónde es posible que un investigador dedicado a las ciencias sociales, que es un ser humano emocional y sociable, al tratar con individuos infinitamente variables y únicos, controle los elementos altamente subjetivos de su investigación (1961, p. 11-14).

Respondiendo a esta cuestión, Piglia afirma que las historias que circulan en una ciudad aportan más información que otro tipo de textos más objetivos, pues en esos relatos encontraríamos no solo una serie de temas que circulan con insistencia, sino unos modos de narrar que nos dirían mucho sobre la construcción cultural de un lugar determinado. Y, para ello, el descubrimiento del grabador representa la ilusión de que puede ser posible captar en un momento dado una serie de voces y una serie de relatos e historias de vida. Por eso se considera tan importante la narración en la etnografía y las historias de vida que intentan recomponer experiencias, porque en la novela, el lector - y el investigador — participan y pueden hacer propia la experiencia que están leyendo, mientras que en la pura información el lector está siempre fuera. Vemos ahí una tensión entre la información —esencialmente objetiva-y los modos de narrar esa información que, al ser narrada, se transforma en experiencia.

La narrativa y la vida van juntas y, por tanto, el atractivo principal de la narrativa como método es su capacidad de reproducir las experiencias de la vida, tanto personales como sociales, en formas relevantes y llenas de sentido. No obstante, esta misma capacidad es, en la investigación educativa, una espada de doble filo la falsedad puede subsistir al significado y a la verdad narrativa utilizando los mismos criterios que produjeron significatividad, valor e intención. No solo se pueden falsificar los datos y escribir una ficción, sino que también se pueden utilizar los datos para contar una mentira tan fácilmente como pueden utilizarse para contar una verdad. (Conelly y Clandinin 2009, p. 43-44)

La fundamentación de la autenticidad de las biografías es un problema harto discutido dentro de la investigación educativa. Las biografías podrían ser absolutamente ficcionales —una novela- . No obstante, debemos tener en cuenta que ficción no es sinónimo de engaño o mentira y que, igualmente, narración no es sinónimo de ficción. El estudio de la narrativa en la in- 
vestigación educativa es un sesgo interdisciplinar y multicultural y, a pesar de las dificultades planteadas por los enfoques biográficos y autobiográficos en la docencia y por la investigación narrativa como metodología (Conelly y Clandinin 1991), se ha abierto un vínculo entre contar historias y explorar la identidad personal y profesional. Sin embargo, la investigación biográficonarrativa pasa por alto que los relatos que despiertan interés en la conciencia pública no son las historias personales que nos cuentan los maestros delante de un grabador, sino relatos, cuentos y novelas escritas que hablan sobre la docencia y el crecimiento personal, construidos de una manera consciente para ser publicados, en la gran mayoría, como biografías, novelas autobiográficas o — pensando en los primeros años de nuestra centuria— publicados también bajo el marbete de "autoficción".

Independientemente de la forma en la que se presentan los testimonios, todos representan experiencias dentro de un texto que, inevitablemente, pondrá en marcha una serie de estrategias retóricas y literarias durante el acto de lectura. Por tanto, es preciso que las investigaciones educativas presten atención a esos elementos literarios. Al respecto, Robert J. Graham (1995, p. 277295) hace notar como la novela autobiográfica de Jonathan Kozol, Death at an early age (1967) fue un éxito tanto editorial como de fuente de estudio para la educación por sus cualidades literarias al mezclar intencionadamente realidad y ficción.

Las dificultades que presenta la investigación biográfico-narrativa en educación referidas a la problemática entre ficción y verdad, encuentran otro tipo de respuestas y contradicciones si nos situamos bajo el paraguas de la investigación literaria. En primer lugar, un problema que puede resultar crucial para un pedagogo es, sin embargo, un problema resuelto para un filólogo. El filólogo lee - e interpreta- desde otra posición: el filólogo no coloca el discurso ficticio por encima del que no lo es ni tampoco lo contrario. Mientras que el pedagogo prestigia las formas del primero sobre el segundo, para el filólogo están al mismo nivel, es decir, reconoce que el valor literario no depende de la forma — género o categoría textual— sino de la manera en que (esas ficciones o no ficciones) son leídas. Esta sería la tesis central que sostienen los trabajos de Hyden White. En El contenido de la forma, White sintetiza, en este caso, el problema de la relación entre el discurso narrativo y el discurso historiográfico.

Esta relación llega a ser problemática para la teoría histórica a partir de la comprensión de que la narrativa no es meramente una forma discursiva neutra que pueda o no utilizarse para representar los acontecimientos reales en su calidad de procesos de desarrollo; es más bien una forma discursiva que supone determinadas opciones ontológicas y epistemológicas con implicaciones ideológicas e incluso específicamente políticas. Muchos historiadores modernos afirman que el discurso narrativo, lejos de ser un medio neutro para la representación de acontecimientos y procesos históricos, es la materia misma de una concepción mítica de la realidad, un "contenido" conceptual o pseudoconceptual que, cuando se utiliza para representar acontecimientos reales, dota a estos de una coherencia ilusoria y de tipos de significaciones más características del pensamiento onírico que del pensar despierto (1995, p. 11).

Hyden White explica que desde Heródoto la historiografía tradicional ha sostenido que la Historia es la suma de relatos "vividos, individuales y colectivos" y que el trabajo fundamental del historiador es "desvelar estos relatos y reescribirlos en una narración” (ibid.). Pero lo importante 
de ello era que la verdad no se encontraba en el texto, sino en el contraste, digamos, entre el texto narrado y el relato oral contado por las personas que habían asistido a los sucesos en cuestión. Sin embargo, la preocupación en nuestro siglo XXI por el ser y por cuestiones de identidad personal tiene que ver con un cambio de paradigmas en la historia de las ideas y del pensamiento filosófico que ha ido de la epistemología a la ontología. La filosofía posmoderna, el "giro lingüístico" y los movimientos historiográficos que cuestionan la capacidad de acceder a la realidad han contribuido no solo a producir interferencias entre los distintos campos del conocimiento sino a enmarañar y desestabilizar los conceptos mismos que rigen nuestra noción de realidad.

Las teorías actuales del discurso disuelven la distinción entre discursos realistas y ficcionales sobre la base de la presunción de una diferencia ontológica entre sus respectivos referentes, reales e imaginarios, subrayando su común condición de aparatos semiológicos que producen significados mediante la sustitución sistemática de objetos significativos (contenidos conceptuales) por las entidades extradiscursivas que les sirven de referente. En estas teorías semiológicas del discurso, la narración resulta ser un sistema particularmente efectivo de producción de significados discursivos mediante el cual puede enseñarse a las personas a vivir una "relación característicamente imaginaria con sus condiciones de vida reales”, es decir, una relación irreal pero válida con las formaciones sociales en las que están inmersos y en las que despliegan su vida y cumplen su destino como sujetos sociales (White H. 1995, p. 12).

Por tanto, las nociones de ficción y no-ficción deben ser consideradas dentro de un amplio proceso de comunicación cultural que articula procesos de emisión y recepción y pone en marcha mecanismos de cooperación lectora específicos (Pozuelo Yvancos 2010), es decir, que atienden a una pragmática lectora. La relación entre ambas es puramente convencional y su distinción "presupone una noción de realidad en la que se identifica "lo verdadero" con "lo real” solo en la medida en que puede mostrarse que el texto de que se trate tenga el carácter de narratividad” (White H. 1995, p. 22). "Concebir de este modo el discurso narrativo — postula Hyden Whitenos permite [...] asegurar la creencia de que la propia realidad social puede servirse y comprenderse de forma realista como relato" (1995, p. 12). En segundo lugar, si “no existe una separación clara entre arte, por un lado, y la vida, por el otro, ni entre relatos y los acontecimientos que esos relatos supuestamente describen” (Ricoeur, 1984, p. 21), ¿todo es ficción? Ser hombres-relato, siguiendo los postulados de Ricoeur, no quiere decir que seamos hombres-mentira, ni el hecho de que las historias de vida tengan estructuras narrativas las exime de mantener una directa relación referencial con la realidad externa a la que aluden. Como ha afirmado Alberca en su estudio acerca de la distinción entre la ficción y las escrituras autobiográficas:

Lo que subyace, en un juicio como éste, es un criterio erróneo, que simplifica más que explica, porque si todo es susceptible de entenderse como ficción, no hay forma humana de reconocer o distinguir ésta, al no disponer de un término de oposición. De este modo, y por la misma razón, se podría decretar que todo es autobiografía, pues si es imposible establecer comparaciones y distinciones, todo es uno y lo mismo (Alberca 2007, p. 46).

En este punto, seguimos los postulados de Alberca al pensar que "la creencia en que la verdad absoluta es inasible puede ser una creencia respetable, pero no parece que sea suficiente para 
igualar los relatos factuales y los ficticios” (2007, p. 57). No obstante, consideramos importante señalar en este punto que las teorías estructuralistas y postestructuralistas, sobre todo las de Hyden White, Foucault, Barthes, Derrida y otros, no niegan la existencia de la historia y de su escritura, como ligeramente se ha afirmado en numerosos estudios, lo que postulan es, en resumidas cuentas, que los discursos de la ficción y los discursos de la historia siguen los mismos patrones narrativos y, por ende, "la jerarquización entre estos dos tipos de discursos es falaz" (Galván 1996, p. 5). Por tanto, como dijimos con anterioridad al señalar la distinción entre ficción y no-ficción, no es que todo sea lo mismo, es que todo es susceptible de interpretarse — de leerse- del mismo modo porque comparte la misma forma. Tal como sostiene el escritor argentino Ricardo Piglia en sus clases sobre Borges,

La ficción no es ni verdadera ni falsa. No se puede verificar. No es como el periodismo que con el acceso a la fuente uno podría verificar si eso es verdad o no. La ficción no pertenece al campo de la verificación, ¿no es cierto? Por lo tanto, no es ni verdadera ni falsa y trabaja con eso. Mantiene esa distinción. No es que todo sea ficción. Lo que hace ver es la vacilación, la dificultad de moverse ahí [...] (Piglia, 2013, s.p).

Piglia, como escritor de ficciones, concibe la realidad subordinada a la ficción. Es por ello que, para el filólogo — para el hombre de letras — no resulta un problema la veracidad del texto ficticio, porque leer desde la ficción es el único lugar para modificar la realidad. "La literatura en este sentido trasciende los límites entre ficción y verdad”, dirá Larrosa (2003, p. 112). La lectura que se realiza desde la crítica académica, la Sociología, la Psicología, la Pedagogía o desde cualquiera del resto de los campos, es una lectura que implica necesariamente una comunidad interpretativa; la ficción, en cambio, va más allá. Leer desde un lugar íntimo, personal, solitario, te permite tener una mirada "esférica" que — como la figura arquetípica del detective- puede ver lo que los otros no ven. Ese es para Piglia un lector único y, también, el último lector porque es el único capaz de cambiar los modos de leer. Por tanto, leer desde dentro la ficción es, al mismo tiempo, leer desde una "zona de borde". "La lectura — dice Piglia — construye un espacio entre lo imaginario y lo real, desarma la clásica oposición binaria entre ilusión y realidad. No hay, a la vez, nada más real ni nada más ilusorio que el acto de leer” (2005, p. 30).

Los estudios literarios que leen desde un enfoque crítico concreto también se centrarían, por ejemplo, en estudiar a Roberto Arlt escritor de ficción del Roberto Arlt cronista. Pero, como apuesta Ricardo Piglia, la crítica literaria también debería leer todos los textos en su conjunto sin tener en cuenta los distintos campos institucionales y, de esa manera, nos ofrece un modo de leer que describiría la discusión entre literatura y enseñanza como un problema de lenguaje sencillo de resolver. Como señala Gudmunsdottir, "los relatos no son nunca meras copias del mundo, como imágenes fotográficas; son interpretaciones” (1995, p. 63). Y como interpretaciones, la senda que recorre el investigador solo puede ser fragmentaria y, en algunas ocasiones, también forma parte de la ficción. Historizar sobre los géneros nos llevaría remontarnos hasta las Confesiones de San Agustín y realizar una revisión crítica de los aportes fundamentales sobre el tema. Por ello, consideramos que un recorrido desde los orígenes del Bildungsroman hasta las manifestaciones del "Yo" en las escrituras contemporáneas, puede decirnos algo acerca de la formación de la condición humana. La Literatura, en este sentido, no tiene objetivos explícitos de enseñanza y no podemos reducirla a ello, pero sí logra hablar del individuo y le ayuda a des- 
cubrir la propia coherencia interna de su consciencia. En este sentido, la ficción no trabaja con pretensiones de verdad, sino con analogías y paralelismos que nos permiten, entre otras cosas, vislumbrar las relaciones fructíferas entre la Literatura y la Pedagogía -y la Educación- como "un itinerario lleno de experiencias, en un viaje de formación que reproduce el modelo de la escuela de la vida o la escuela del mundo, pero es también, a la vez, un viaje interior de autodescubrimiento, de autodeterminación y de autorrealización” (Larrosa, 1996, p. 114).

\section{NOVELA Y FORMACIÓN: EL SUJETO EN EL BILDUNGSROMAN}

El origen del Bildungsroman — 'bildung' (período de formación posterior a la fase correspondiente a la enseñanza primaria) y 'roman' (novela) — se vincula a un programa filosófico destinado a la idea de formación del ciudadano y a un canon nacional — la Ilustración alemana y el clasicismo de Weimar-, pero anticipa también los cambios que iban a producirse a lo largo del siglo en torno al sujeto moderno y que culminarían con la unificación de la nación.

El término Bildungsroman aparece por primera vez en Vida de Schleiermacher (1870) de Wilhelm Dilthey. Este fue uno de los precursores en esa recuperación de las grandes figuras literarias de finales del XVIII. Lleva a cabo una revisión del Bildungsroman a través de su análisis del Hiperión de Hölderin que se convertirá en una referencia obligada de la tradición crítica sobre el género inmediatamente posterior. En su estudio, Dilthey ubica la aparición de la novela de formación bajo el influjo de Rousseau, como respuesta a la "tendencia de nuestro espíritu durante esta época hacia una cultura interior del hombre” (Dilthey 1978, p. 369).

El concepto de Bildungsroman surgió en Alemania a finales del siglo XVII como un intento de reencontrar formas de pensar de nuevo al sujeto. No obstante, la problemática acerca de su origen, su definición y los contornos que lo delimitan es lo suficientemente compleja como para pretender ofrecer una caracterización lo bastante completa en este artículo, el cual aspira a otros intereses. Un breve recorrido por los principales estudios críticos que abordan el Bildungsroman nos revela dos dificultades importantes. La primera tiene que ver, como mencionamos, con el debate terminológico que se ha creado fuera del ámbito de los estudios germánicos. La novela de formación ha sido también llamada novela de aprendizaje o novela de desarrollo del hombre (Bajtín, 1989), novela pedagógica (Larrosa 1996, 2003) —cuando el autor tiene como propósito educar-, o novelas sobre educación — cuando su argumento se centra en el proceso educativo- También encontramos, aunque menos frecuente, la denominación de novela de iniciación, la cual proviene de la novela de Novalis, Enrique de Ofterdingen (1802). Independientemente de la traducción o denominación con la que designemos al género, nos encontramos con la segunda dificultad cuando pretendemos precisar su alcance, es decir, su caracterización y las novelas que sirven como modelos de dicha caracterización.

De manera general, podemos afirmar que el Bildungsroman se caracteriza por una estructura que acompaña el desarrollo del héroe desde su juventud hasta su madurez, "subrayando todos aquellos episodios que jalonan la progresiva construcción de su conciencia y de su identidad" (Escudero 2008, p. 2). Ahora bien, esta segunda dificultad viene dada por la ambigüedad del género (de Diego 1998), porque nunca sabemos del todo a quién es aplicable el aprendizaje que la novela misma conlleva: al personaje o al lector. La estructura de desarrollo en la novela de forma- 
ción responde a una intención didáctica para con el lector, ya Karl Morgensterns en su definición de Bildungsroman asocia el objetivo estético y pedagógico, vinculando la formación del héroe a la formación del lector. En este sentido, advertimos que los estudios críticos señalan una doble tradición: unas novelas ponen énfasis en el aprendizaje del lector como ciudadano y otras simplemente en la formación del protagonista en un sentido ficcional. Cuando se da el primer caso, los textos adoptan un carácter más ensayístico y parecen formular de modo explícito el carácter propedeútico. Tenemos como ejemplo el Emilio de Rousseau. En el segundo caso — el aprendizaje del protagonista - lo propedeútico adquiere un carácter explícito (de Diego 1998, p. 3). El modelo fundador sería entonces el Wilhem Meister de Goethe. Si tenemos en cuenta las reseñas que la crítica ha consagrado a esta novela, veremos que su repercusión ha sido y es incuestionable y, se la considera la primera novela de formación y, por tanto, toda novela que se inscriba dentro de este género debe seguir el modelo del Meister. Pero lo que nos interesa verdaderamente para el análisis del presente trabajo es la cuestión de la función de dicho género. ¿Existe una transformación en el personaje que puede ser transferida al lector como experiencia de vida?

Consideramos que los estudios sobre el héroe de la novela de formación a partir de las consecuencias derivadas de la crisis del sujeto y el giro lingüístico que inciden especialmente en el pensamiento filosófico y estético a partir de finales del XIX pueden, quizás, ayudarnos a responder a esta pregunta. Desde la perspectiva de la teoría literaria, Bajtín en "La novela de educación y su importancia en la historia del realismo" (1979) da cuenta de que existe en dichas novelas una traslación del héroe en el espacio por medio de una jerarquía social: va de vagabundo a rico, pero señala que el héroe no sufre transformación personal alguna, "los acontecimientos truecan su destino, cambian su posición en la vida y en la sociedad, pero el héroe permaneces sin cambios, igual a sí mismo” (1989b, p. 211). Para Bajtín, lo único que el héroe puede percibir es su concepción de individuo histórico y su relación con su época, su lugar en el mundo y sus circunstancias. Según Gómez (2002) y Escudero (2008), en el Wilhem Meister tampoco se describen los acontecimientos históricos que rodean al protagonista ni se aluden a ellos, pues su figura es simplemente la representación de la identidad nacional alemana de la época.

Desde una perspectiva filosófica, Paul Ricoeur (1984) plantea que todos luchamos en la narrativa de nuestra vida por recrear las mismas características de las historias o los relatos épicos: un principio, un medio y un fin, entrelazados de manera coherente. Las ideas de Ricoeur manifiestan, de manera general, que el sujeto posee una identidad performativa "que nos dice que para ser necesito construir un texto". A partir de estas premisas los estudios sobre el Bildungsroman empiezan a cruzarse con los estudios autobiográficos y otro tipo de manifestaciones artísticas posteriores y "empiezan a leerse como el trayecto de un volver a sí mismo a partir de ser Otro" (Fontela, 1996). También el crítico norteamericano Northrop Frye ha aportado hipótesis interesantes a la cuestión al asociar, dentro de la novela de formación, la dependencia de la vida del escritor y los deseos del personaje. Según las ideas de Frye, un escritor nunca es libre cuando cuenta una historia o un mito de pura imaginación, porque está obligado a adaptar su historia a la conciencia del lector, a las cosas tal como son en el mundo físico y, propone la novela como el modo que brinda el "núcleo estructural [...] de la visión que el hombre tiene de su vida como búsqueda” (1976, p. 15). 
En el ámbito español, es capital para esta investigación la contribución de Rodríguez Fontela, quien en su exhaustivo y brillante estudio La novela de autoformación. Una aproximación teórica e histórica al Bildugsroman desde la narrativa hispánica (1996), propone un nuevo modo de denominar al género que no solo es aplicable al proceso de construcción de la identidad individual del personaje ficcional, sino también al proceso autoformativo de la humanidad: novela de autoformación. Su trabajo se apoya en la hipótesis de Ricoeur según la cual la humanidad descubre su identidad en las narraciones que se cuenta a sí misma sobre sí misma y, desde esa premisa, examina los orígenes y la historia de nuestro discurso novelesco, presenta las configuraciones históricas del género de autoformación y, al mismo tiempo, descubre en las narraciones ficticias el proceso de autoformación de la colectividad humana en la cultura occidental.

Gracias a los mencionados estudios se advierte que la evolución del sentido y el significado de la novela subrayan la del mismo héroe. Por tanto, durante el siglo XX veremos la conversión del protagonista en su propio narrador, como se puede comprobar, por ejemplo, en Retrato del artista adolescente (1914) de Joyce o El guardián entre el centro (1951) de Salinger. De hecho, el propio personaje solo es capaz de comprender su propia identidad a través de ese proceso de "narrarse a sí mismo", de modo que aportaciones filosóficas como las de Ricoeur son fundamentales para el estudio del Bildungsroman. No obstante, tengamos en cuenta que el Bildungsroman ni es una novela filosófica ni una novela pedagógica aunque permita múltiples lecturas y, esto es así, porque la estructura antropológica que lo sustenta es una metonimia aplicable al desarrollo mismo de la novela. Así, toda novela es una alegoría de la enseñanza como búsqueda; de la formación como experiencia vivida y como conocimiento del ser. Por tanto, consideramos que el término Bildungsroman, más que delimitar un género literario, responde a una estructura mítica —un mítema, podríamos decir — del desarrollo del hombre; un mito iniciático sobre la formación y el aprendizaje presente en todas las culturas.

\section{ESCRITURAS DEL YO}

Hablar de novela y formación implica también adentrarse en una red de "escrituras del Yo" sostenidas por la memoria, un terreno movedizo en el que el significado de una congruencia entre el mundo del autor, la mecánica del narrador o personaje, se disuelven en los bordes de los géneros conocidos, a veces de difícil distinción, donde el yo autoral es el objeto de máximo interés, como la autobiografía, las memorias, las epístolas, el diario, el ensayo y el autorretrato. En síntesis, lo que hemos preferido llamar, siguiendo a Piglia, "escrituras del Yo". Estas manifestaciones literarias fueron soslayadas por la crítica durante un largo periodo de tiempo en favor de los géneros de la ficción hasta su consolidación a finales del siglo XIX y comienzos del XX. Pero no será hasta la segunda mitad de siglo XX cuando asistamos a un auge de autobiografías y memorias tanto en el mundo académico como editorial. Las "escrituras del Yo", tal como hemos preferido llamarlas, se definen por mantener una relación ambigua con respecto de lo real y lo vivido y, por lo tanto, no podemos estudiarlas ni comprenderlas en su especificidad sin considerar las relaciones extratextuales entre el texto (graphé) y la vida (bios) que ese mismo texto denota.

El saber de experiencia no está, como el conocimiento científico, fuera de nosotros, sino que solo tiene sentido en el modo como configura una personalidad, un carácter, una sensibilidad o, en definitiva una forma humana singular que es a la vez una ética (un modo de conducirse) y una estética (un estilo) (Larrosa 1996, p. 24). 
Tanto la Educación como la Crítica y la Teoría literarias se han preocupado insistentemente por trazar estos límites entre la autobiografía y la ficción en los nuevos textos híbridos catalogados bajo el nuevo marbete de "autoficción”. Más que definir el término, qué es o qué no es autoficción, consideramos que, intentar dilucidar por qué sucede esto es una cuestión más importante. No qué es, sino por qué es así; por qué asistimos a una disolución de las fronteras genéricas y por qué, desde aproximadamente los últimos treinta años, los lectores vienen reclamando este tipo de textos. La imposibilidad de diferenciar la autoficción por sí misma incide en la inexistencia de rasgos pertinentes que permitan distinguirla de la novela o de la autobiografía, puesto que estos géneros literarios cada vez comparten más técnicas narrativas y han llegado a ser, desde el punto de vista formal, indistinguibles. Por tanto, no entendemos aquí la autoficción, como un mero género, sino como un mecanismo literario que va más allá, un modo de narrar específico que exige, a su vez, un modo de leer activo que entiende a la narración de modo transversal, cruzada por todas las experiencias posibles, y cuyos límites están marcados siempre por su lectura. La autoficción de manera sintética, trabaja de dos modos: o camufla un relato autobiográfico bajo la denominación de novela, o bien, simula que una novela parezca una autobiografía. El autor juega con afirmar y negar su identidad al mismo tiempo, y juega a aletear los límites de la ficción introduciendo prólogos, notas aclaratorias, jugando con los paratextos, etc. Así, provoca un choque de pactos antitéticos que inducen la ambigüedad al no saber el lector, en un principio, a qué pacto debemos atender (Alberca, 1996, p. 9-19)”. Un efecto de ambigüedad que se prolongará cuanto más sutil sea la mezcla de géneros lo que hace que el lector se pregunte: “¿Podría ser la autoficción el reconocimiento explícito de que cuando se narra la vida propia es imposible no hacer ficción?” (Alberca 2005, p. 126). Esta incógnita nos retorna de nuevo a la problemática que presentaba la investigación biográfico-narrativa, y es que existe todo un contexto estético-filosófico y una teoría posmoderna sobre el tejado de todos los campos de estudio que produce fuertes cambios epistemológicos. Pero, puesto que este trabajo pretende alejarse de disquisiciones filosóficas en cuanto a cuestiones de identidad, no se prolongará aquí el debate metafísico, solo señalaremos la certeza con la que Pozuelo Yvancos indica que una de las corrientes más importantes sobre el pensamiento autobiográfico es aquella defendida por Barthes, Derrida o De Man, la cual sostiene que "toda narración es una forma de ficcionalización, inherente al estatuto retórico de la identidad y, en concomitancia con una interpretación del sujeto como esfera del discurso" (2006, p. 17). Por tanto, ante la dominancia del pensamiento posmoderno, la autoficción nos sirve como recurso para auto-construirnos y, sobre todo, para ironizar el proceso de aprendizaje de la novela de formación, con la intención de concluir que el autoconocimiento de un Yo unificado y estable es imposible. Esa búsqueda existencial del yo se vuelve gracias a los recursos metaficcionales en una etnografía de la lectura. La autoficción, podemos concluir, es un modo de leer y de leerlo todo como "ficticio y verdadero simultáneamente” (Alberca, 1996, p.180), pero considerando siempre los límite entre el discurso factual y el ficticio. Al igual que la información solo puede ser ordenada por la narración, la ficción lo único que puede ordenar es la experiencia. Así, la experiencia queda siempre subordinada por la ficción que la transforma en lenguaje mediante una poética de lectura que sirve como herramienta de interpretación y que consiste en leerlo todo como ficción. Lo que no quiere decir que todo sea ficción.

\section{CONCLUSIONES: LA FICCIÓN PARA RECONSTRUIR LA EXPERIENCIA}

A partir de los años 70 del pasado siglo hemos asistido, tanto en los estudios literarios como en las investigaciones educativas, no solo a un "giro narrativo" (McEwan y Egan 1995) sino a un 


\section{E S T U D I O Y E N S A O S}

"giro autobiográfico" que aparece como una consecuencia más de la importante herencia romántica que ha gestado el panorama literario contemporáneo (desde el Bildungsroman hasta la autoficción). El espacio autobiográfico, como hemos visto, acoge obras diversas de diversas modalidades que resultan complejas en su definición y caracterización, y, en consecuencia, se van difuminando las fronteras que encorsetaban estos subgéneros dentro de unos moldes fijos por la incursión de elementos ficcionales subordinados a una nueva manera de entender al sujeto y al mundo. Así, la ficción ha invadido lo factual de tal forma que no nos ofrecería respuestas convertirnos en detectives para intentar discernir entre lo factual y lo ficcional. Es una batalla perdida. Lo importante no es, como dijimos, el grado de veracidad del texto, sino qué efecto provoca en la realidad. ¿Puede la ficción transformar la realidad? Ahí radica la importancia de la narrativa y de la ficción en la investigación educativa. No en hacer una análisis pedagógico de la novela de formación y de las autobiografías pensando en la posibilidad formativa que esas ficciones pueden provocar en los lectores, puesto que no podemos demostrar de ningún modo que estos lectores se forman por medio de dichas lecturas, sino considerar que la novela de formación y las “escrituras del Yo" nos permiten, en primer lugar, reconstruir la evolución del pensamiento de un sujeto particular y, por ende, su desarrollo en la formación intelectual y personal, y en segundo lugar —y de manera muy lateral—, que la lectura de las experiencias de otro pueden aportar algo a nuestra propia experiencia.

Por lo tanto, novela y enseñanza como línea de investigación en una zona de borde disciplinar entre los estudios literarios y la pedagogía, implica no entender las novelas como texto para que los alumnos encuentren una enseñanza para sus vidas, sino como fuentes primarias para un estudio pedagógico e histórico acerca de la formación humana. Porque, como hemos tratado de argumentar en este trabajo, la narración es consustancial al ser humano. Como sostiene el filósofo Odo Marquard

¿Tiene futuro la narración? ¡O acabará pereciendo por la creciente objetivación científica, técnica, económica e informacional del mundo moderno? No creo en la tesis de su muerte, sino que opino: cuanto más moderno es el mundo moderno, más imprescindible resulta la narración. Narrare necesse est: los seres humanos tenemos que narrar. Esto es y será así. Porque los seres humanos somos nuestras historias, y las historias tienen que narrarse (2001, p. 63).

Y desde esta perspectiva, la novela de formación es un género justo para analizar "qué lugar ocupa la literatura en la educación del personaje; y en consecuencia, qué relación se establece entre educación y literatura” (De Diego, 2007, p. 294).

\section{REFERENCIAS}

Alberca, M. (2005). ¿Existe la autoficción hispanoamericana?, Cuadernos del CILHA, 7(7-8), 115-127.

Alberca, M. (2007). El pacto ambiguo: de la novela autobiográfica a la autoficción. Biblioteca Nueva.

Allport, G. (1977). La personalidad: su configuración y desarrollo. Herder.

Bain, K. (2007). Lo que hacen los mejores profesores de universidad. Universitat de València. 


\section{EST UDIOS Y ENSAYOS}

Bajtín, M. (1989). Teoría y estética de la novela. Taurus.

Connelly, M. y Clandinin, J. (1988). Teachers as curriculum planners: Narratives of experience. Teachers College Press.

Connelly, M. y Clandinin, J. (1990). Stories of experience and narrative inquiry. Educational Researcher, 19(5), 2-14.

Connelly, M. y Clandinin, J. (1991). Narrative inquiry: Storied experience. Short, C. (ed.). Forms of curriculum inqury. State University of New York Press, pp. 121-153.

Connelly, M. y Clandinin, J. (2009). Relatos de experiencia e investigación narrativa. Larrosa, J. et. al. (ed.). Déjame que te cuente. Ensayos sobre narrativa y educación. Laertes, pp. 11-59.

Diego, J.L. de (1998). La novela de aprendizaje en Argentina. Primera parte, Orbis Tertius, año III, 6, 1-19. file://C:/Users/raquel/Downloads/2734-1-5536-1-10-20131018\%20(1).pdf

Diego, J. L. de (2007) Literatura y educación: la novela de aprendizaje. Arrabal, 5, pp. 293-298.

Dilthey, W. (1978). Obras de Wilhelm Dilthey IV. Vida y poesía. Fondo de Cultura Económica.

Egan, K. (1995). Narrativa y aprendizaje. Una travesía de inferencias. McEwan, Hunter y Egan, Kieran (comp.) La narrativa en la enseñanza, el aprendizaje y la investigación (169-180). Amorrortu.

Elbaz, F. (1990). Teachers' participation in curriculum development. Lewy, A. The International Enciclopedy of Curriculum. Pergamon Press, pp. 365-367.

Escudero, V. (2008). Reflexiones sobre el sujeto en el primer Bildungsroman. Tesis inédita. Universitat de Barcelona.

Frye, N. (1976). Anatomía de la crítica: cuatro ensayos. Monte Ávila.

Galván, F. (1996). Ficción histórica y metaficción historiográfica: el caso inglés. 1616: Anuario de la Sociedad Española de Literatura General y Comparada, 10, pp. 91-98.

Gerbaudo, A. (2009). Literatura y enseñanza. Dalmaroni, M. (ed.). La investigación literaria. Problemas de una práctica. Editorial UNL, pp. 158-181.

Gómez García, J. (2002). Sobre el concepto de formación en el Wilhelm Meister de Goethe. Revista Educación y Pedagogía, 32(XIV), 41-51.

Goodson, I. F. (1981). Life history and the study of schoolin. Interchange, Institute for Studies in Education, $4(11), 69$.

Goodson, I. F. (ed.) (2004). Historias de vida del profesorado. Octaedro.

Goodson, I. F. y Hargreaves, A. (1996). Teachers' profesional live. Falmer Press.

Goodson, I, F. y Sikes, Pat (1991). Life History Research in Educational Setting: Learning from lives. Open University Press.

Goodson, I. F. y Walker, R. (1995). Contar cuentos. McEwan, H. y Egan, K. (comp.) La narrativa en la enseñanza, el aprendizaje y la investigación (260-273.). Amorrortu.

Graff, G. (1987). Professing Literature. An institucional History. The University of Chicago Press. 


\section{EST U D I S Y E N A Y O S}

Graham, R. J. (1995). Historia de la enseñanza como tragedia y novela. McEwan H. y Egan, K. (comp.) $L a$ narrativa en la enseñanza, el aprendizaje y la investigación (274-294). Amorrortu.

Gudmundsdottir, S. (1995). La naturaleza narrativa del saber pedagógico sobre los contenidos. McEwan, H. y Egan, K. (comp.) La narrativa en la enseñanza, el aprendizaje y la investigación. Amorrortu.

Hargreaves, D. (1999). The Knowledge-Creating School, British Journal of Educational Studies, 2(47), 122144.

Huberman, M. (1995). Trabajando con narrativas biográficas. McEwan, H. y Egan, K. (comp.) La narrativa en la enseñanza, el aprendizaje y la investigación (183-235). Amorrortu.

Jackson, P. W. (1995). Sobre el lugar de la narrativa en la enseñanza. McEwan H. y Egan, K. (comp.) $L a$ narrativa en la enseñanza, el aprendizaje y la investigación (25-51). Amorrortu.

Kundera, M. (1986). El arte de la novela. Titivillus (editor digital).

La Farge, O. (1961). Prefacio. Lewis, O. Antropología de la pobreza. Fondo de Cultura Económica.

Larrosa, J. (1996). La experiencia de la lectura. Estudios sobre literatura y formación. Laertes.

Larrosa, J. (2003). Entre las lenguas: lenguaje y educación después de Babel. Laertes.

Lukács, G. (1971). Teoría de la novela. Edhada.

Macintyre, A. (1985). After virtue. Notre Dame. University of Notre Dame Press.

Marquard, O. (2001). Filosofía de la compensación. Ensayos sobre antropología filosófica. Paidós.

McEwan, H. (1995). Las narrativas en el estudio de la docencia. McEwan, H. y Egan, Kieran (comp.) La narrativa en la enseñanza, el aprendizaje y la investigación (236-259). Amorrortu.

Moretti, F. (1987). The way of the world: The Bildungsroman in European Culture. London: Verso.

Piglia, R. (2005). El último lector. Anagrama.

Piglia, R. (2012). Escenas de la novela argentina. Clases de Literatura. TV pública argentina. Biblioteca Nacional. https://www.youtube.com/watch?v=mKOENCrDBOQ

Piglia, R. (2013). Borges por Piglia. TV pública argentina. Biblioteca Nacional. https://www.youtube.

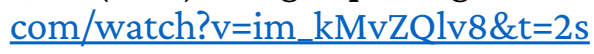

Pozueo Ivancos, J. Ma (2006). De la autobiografía: teoría y estilos. Crítica.

Pozuelo Ivancos, J. Ma (2010). La ficción en la poética contemporánea. Poética de la ficción. Síntesis, pp. 63-150.

Ricoeur, P. (1995). Tiempo y nación. Siglo XXI Editores, 2 vol.

Ricoeur, P. (2015). Historia y verdad. Fondo de Cultura Económica.

Rodríguez Fontela, M. A. (1996). La novela de autoformación: una aproximación teórica e histórica al Bildungsroman desde la narrativa española. Reichenberger.

Saer, J. J. (1997). El concepto de ficción. Espasa Calpe.

Spencer, H. (1900). Educación intelectual, moral y física. F. Sempere y Compañía. 


\section{EST UDIOS Y ENSAYOS}

White, H. (1995). El contenido de la forma. Paidós.

White, H. (2003). El texto histórico como artefacto literario y otros escritos. Paidós.

White, R. (1952). Live in progress: a study of the natural growth of personality. Dryden Press.

Znaniecki, F y Thomas, W. (1984). Introduction. The Polish Peasant in Europe and America. University of Illinois Press. 